\title{
Optical Coatings as Mirrors for Optical Diagnostics
}

\author{
L. Marot ${ }^{1, *}$, G. Arnoux ${ }^{2}$, A. Huber ${ }^{3}$, V. Huber ${ }^{4}$, Ph. Mertens ${ }^{3}$, G. Sergienko ${ }^{3}$, E. Meyer ${ }^{1}$ and \\ J.E.T. Contributors ${ }^{\dagger}$
}

${ }^{1}$ Department of Physics, University of Basel, Klingelbergstrasse 82, CH-4056, Basel, Switzerland

${ }^{2}$ CCFE, Culham Science Centre, Abingdon, Oxon, OX14 3DB, UK

${ }^{3}$ Forschungszentrum Jülich GmbH, Institut für Energie- und Klimaforschung - Plasmaphysik, D-52425 Jülich, Germany

${ }^{4}$ Jülich Supercomputing Centre, Research Centre Jülich, D-52425 Jülich, Germany

\begin{abstract}
The aim of this work was to provide a comprehensive insight concerning coated films which might be used for first mirrors in ITER. The influence of the mirror crystallite size has been addressed as well as the coating techniques to provide nanocrystalline films. Tests of coated mirrors both in laboratories and in tokamaks are reviewed. For the tokamak tests a wide angle camera system has been installed in JET-ILW which is composed of a mirror box with 3 stainless steel mirrors coated with rhodium viewing the torus through a conically shaped aperture. The system delivered the required image quality for plasma monitoring and wall protection. No or insignificant degradation of the optical transmittance has been observed during the experimental campaign in 2014 with about 3000 plasma pulses in different magnetic field configurations.
\end{abstract}

Received on 18-09-2015 Accepted on 28-10-2015 Published on 05-01-2016

Keywords: First Mirrors, ITER, Mo, Rh coating, JET wide angle viewing system.

\section{INTRODUCTION}

In current fusion experiments the plasma is often viewed directly, which will not be possible in future tokamaks (e.g. ITER) due to the high level of neutron radiation expected. Therefore, metallic mirrors are foreseen to play a key role in guiding the plasma light towards the optical diagnostics. As these so-called first mirrors (FM) directly view the plasma, they will be subjected to a harsh environment of particle fluxes due to charge exchange neutrals and neutrons, as well as UV, $\mathrm{x}$-ray and gamma radiation [1].

Molybdenum (Mo) and rhodium (Rh) are two important candidate materials for FM, especially in ITER. Molybdenum, due to its low sputtering yield, is more advantageous under erosion conditions [2]. Rhodium, on the other hand, provides a better reflectivity (between $70-80 \%$ ) in the visible range [3] as well as near-infrared and infrared ranges (around $85 \%$ at $1 \mu \mathrm{m})$. Rh has also low chemical reactivity, preventing oxide and carbide formation $[4,5]$. In the case of polycrystalline mirrors composed of many grains with random orientation of

"Department of Physics, University of Basel, Klingelbergstrasse 82, $\mathrm{CH}-4056$, Basel, Switzerland; Tel: +41 (0)61 267 3720; E-mail: laurent.marot@unibas.ch

†'See the Appendix of F. Romanelli et al., Proceedings of the 25th IAEA Fusion Energy Conference 2014, Saint Petersburg, Russia. faces, the sputtering yield can vary strongly over the material surface depending on the crystallographic plane of each individual grain and its orientation with respect to the incoming particle flux [6-9]. It is also important to keep the surface relief pattern i.e. the roughness of a polycrystalline mirror small compared to the wavelength of the reflected light in order to minimize the effect of diffuse reflection on the measurements [10]. Generally, this indicates that the mirrors must have small grain sizes and preferably similar crystal orientation to be homogeneously sputtered. These requirements can be fulfilled, for instance, by using a single crystal or by coating the surface with nanometer-size crystallites. Moreover, test of amorphous metal alloy mirrors were carried out under ion bombardment. These mirrors have no crystalline structure and after long-term sputtering the initial optical quality was maintained [9, 11, 12]. However, there is a critical difficulty with the possibility of recrystallization due to hydrogen embrittlement, to significantly reduced performance. This may rule out the use of current alloy in large scale fusion experiments, but new amorphous alloys might be developed with a greater resistance to recrystallization. Due to technological difficulties in producing large size Mo single crystals [13], coating might be considered as an alternative. 


\section{REALISATION OF COATED MIRRORS}

The preparation of such coated mirrors was reported by magnetron sputtering [3, 14], evaporation [15] and pulsed laser deposition (PLD) [16-18] technique for Rh, Mo and W coatings. Silver and aluminum coatings with a thick protective dielectric layer with low rate of sputtering and chemical modification $\left(\mathrm{Al}_{2} \mathrm{O}_{3}, \mathrm{ZrO}_{2}\right)$ were also investigated $[19,20]$. The $\mathrm{ZrO}_{2}$ films deposited at room temperature were found to have good homogeneity without microcrystalline inclusions. The observed needle-like pores in $\mathrm{ZrO}_{2}$ may provide a path for hydrogen transport through the film, inhibiting its accumulation at the oxide-metal interfaces and therefore preventing blister formation [20]. Several proven techniques offer the possibility to produce coated mirrors at least on a laboratory size (tens of centimeters) with nanometric crystallites and a dense structure. The peculiar PLD capability to tailor film structure at the nanoscale gives the possibility to deposit low roughness Rh films with a wide variety of structures (polycrystalline, highly oriented and amorphous) and morphologies. This technique allow to deposit planar and homogeneous Rh films effectively suppressing surface defects on areas of the order of $10 \mathrm{~cm}^{2}$ with a satisfactory specular reflectivity. For all the techniques previously mentioned the optical properties of the coated films are similar to the theoretical one. Industrial-type ITER FM mock-ups prepared by magnetron sputtering have already been manufactured [21]. A total of eight cooled fullscale ITER mirrors of $109 \mathrm{~mm}$ diameter have been manufactured by magnetron sputtering technique. The polishing quality achieved is characterized by a flatness error lower than $0.1 \mu \mathrm{m}$ root mean square and roughness lower than $2 \mathrm{~nm}$. The spectral reflectance of the coating deposited by magnetron sputtering reaches the theoretical values for both the molybdenum and rhodium layers. However, the mirror flatness error (defined in peak to valley in wave measured with interferometer at a wavelength of $633 \mathrm{~nm}$ over $90 \mathrm{~mm}$ diameter) has significantly increased in comparison to the polished substrate due to the coating process, which shows that sample and/or target rotation during deposition is needed.

\section{LABORATORY TESTS}

Mo and Rh coated mirrors were tested in laboratory in terms of their mechanical properties i.e. adhesion to the substrate $[17,22]$, chemical reactivity towards typical tokamak impurities (like oxygen or carbon from residual gas fractions with partial pressure $<5 \times 10^{-8}$ ) mbar or elements eroded from the first wall (like tungsten) [4, 5, 23-25]. It appeared that the adhesion increased with increasing substrate hardness and increasing deposition temperature for the magnetron deposition technique. For PLD the highly-oriented polycrystalline film structure guarantees the best adhesion to the substrate while a higher cohesion is achieved in the amorphous-like film [17]. Ion bombardment and especially deuterium plasma exposures were performed for Mo and Rh mirrors [26-28]. For example, $200 \mathrm{eV} \mathrm{D}^{+}$exposures of coated molybdenum mirrors causes no significant mechanical damage such as blistering of the coating or increase of the surface roughness. The drop of reflectivity may be explained with the complex permittivity $\varepsilon=\varepsilon 1+i \varepsilon 2$. The smaller decrease in $\varepsilon 1$ (the real part of the permittivity) of exposed mirrors with increasing wavelength is attributed to a shorter intraband relaxation time compared with virgin mirrors. This suggests enhanced light scattering, which can be attributed to surface and grain boundary scattering, defects, and impurity scattering. Since the diffuse reflectivity measured by the spectrophotometer does not increase after any of the exposures, surface and grain boundary scattering are negligible. The lower amplitude of $\varepsilon 2$ (the imaginary part of the permittivity) of exposed mirrors compared with virgin mirrors for lower wavelengths is attributed to weaker optical absorption associated with the interband transitions. This is also due to a higher concentration of deuterium and deuterium induced defect in the subsurface layers of molybdenum mirrors as a result of implantation [25]. Mo coatings will remain functional in most of the cases in ITER, mainly no strong reflectivity degradation (higher as $10 \%$ ). However, changes in the expected conditions such as $500 \mathrm{eV}$ mean energy of impinging charge exchange neutrals or $<100$ ${ }^{\circ} \mathrm{C}$ surface temperature of the mirrors can lead to gradual or sudden failure of the coatings, mainly a complete loss of the reflectivity [29]. It has to be taken into account for dust deposition on the mirror, the life time will be reduced [30] and is described in the next section for tokamak exposed mirrors. This was leading to extensive research as reviewed by Voitsenya et al. [9]. Rh mirrors exposed to $D_{2}$ plasma show a drop in the reflectivity which can be associated with a formation of a subsurface rhodium deuteride $\left(R h D_{x}, x \leq 2\right)$, which has optical constants different to those of Rh [25]. After exposure to a total ion fluence of $1.6 \times 10^{20} \mathrm{~cm}^{-2}$ less than $10 \%$ reflectivity losses was observed indicating that this mirror will remain functional for ITER. Crystal structure and morphology of rhodium films strongly affect the change of the specular reflectivity during exposure to deuterium plasmas [27]. In particular, films with few $\mathrm{nm}$ crystallite size and granular-like morphology prevent the reflectivity degradation, probably as a consequence of the inhibition of rhodium deuteride sub-superficial layer formation. The roughness all films evaluated from the Atomic Force Microscopy (AFM) images remains on the order of that of the stainless steel substrate (few nanometers) even after the deuterium plasma exposure. This is consistent with the diffuse reflectivity measurements which exhibit values below $3 \%$ in the range of wavelength of 250-2500 nm for every Rh films both before and after the exposure. Moreover, as reported mock ups including water cooling were realised [21] and recently exposed to $\mathrm{H}_{2} / \mathrm{Ar}(90 / 10 \%)$ plasma in the Magnum-PSI linear plasma device [31]. Roughening of the coated mirror surface is flux and temperature dependent i.e. at RT implanted hydrogen cannot easily diffuse along the grain boundaries towards the surface. This increases the dynamic hydrogen inventory in the layer and thus its tendency to blister. Mo 
mock ups of coated mirrors exposed in Magnum-PSI show a high diffuse reflectivity after $\mathrm{H}_{2} /$ Ar plasma inducing a specular reflectivity loss at $500 \mathrm{~nm}$ higher than $60 \%$. In case of water cooled mock ups with $5 \mu \mathrm{m}$ Rh films, at a flux of $3 \times 10^{23} \mathrm{~m}^{-2} / \mathrm{s}$ the coating delaminated which is not seen for $1 \mu \mathrm{m} \mathrm{Rh}$ film. Rh films showed a high compressive stress of $-2.5 \mathrm{GPa}$ leading to a poor film adhesion on stainless steel substrate due to an important available energy per area stored in the unbuckled film for the thicker film. Furthermore, Mo and Rh coated mirrors on SS substrate were irradiated under neutrons $(0.1 \mathrm{dpa})$ in the materials testing reactor BR2 and analyses are ongoing [32]. As first results, the reflectivity losses in the range $250-2500 \mathrm{~nm}$ were not more than few percent.

\section{TOKAMAK EXPOSURES}

Tests were carried out in TEXTOR [3, 33, 34], DIII-D [35], JET-C [36, 37] and JET-ILW [38] showing no critical failure of the coated mirrors like delamination or strong degradation of the optical properties. For example in TEXTOR for Rh coated mirror exposure, the film survived under erosion conditions although the reflectivity was decreased by $8 \%$ at $250 \mathrm{~nm}$ after exposure [3]. For another exposure of a Mo coated mirror, a $2.5 \%$ degradation of reflectivity in the UV range was noticed under erosion after an exposure fluence of $1.4 \times 10^{25}$ ions $/ \mathrm{m}^{2}$. Mostly, Rh and Mo coated mirrors were investigated, also in JET during the 2013-2014 campaign. In previous studies in the JET-C wall configuration, Rh coatings with an initial reflectivity $30 \%$ better than that of pure Mo survived the test without detachment, however, their post-exposure reflectivity was the same as that of the exposed Mo surfaces [36]. Results of JET-ILW mirrors exposure in the main chamber wall show for Rh mirror surfaces originally having very high reflectivity a significantly reduced performance $(25 \%$ at 250 $\mathrm{nm}$ ); reflectivity is now at a level typical for Mo polycrystalline mirrors in most of the spectral range under examination. For all materials degraded performance is observed in the entire spectral range $(250-2500 \mathrm{~nm})$, but the most significant decrease is in the UV range $(250-400 \mathrm{~nm})$ [38]. Despite these results no further experiments from the JET First Mirror Test were started in 2013 and 2014. However, optical systems using coated mirrors for plasma monitoring and wall protection are used nowadays in JET-ILW; this last point is developed in the present paper including characterizations of these mirrors.

\section{WIDE ANGLE VIEWING SYSTEM AT JET-ILW}

After the previous examples of tokamak tests of coated mirrors it was important to demonstrate a complete optical diagnostic system operating in a metallic tokamak and especially at JET. During the JET-ILW shutdown a wide angle camera system has been installed [39] in the horizontal mid-plane of the low field side with the field of view shown in the figure 6 of reference [39]. The 2011-2012 campaigns exposure lasted $18.9 \mathrm{~h}$ in total with approximately $13.1 \mathrm{~h}$ of
$\mathrm{X}$-point operation and after that the mirrors were exposed also to $19 \mathrm{~h}$ in total with $12 \mathrm{~h}$ of $\mathrm{X}$-point operation for the 2013-2014 campaigns. This system, composed of a mirror box with 3 stainless steel mirrors coated with Rh, is attached to the vacuum vessel wall on the low field side of the JET torus. The mirror system contains two branches, a lower and an upper branch. Each of the branches viewing half of the machine through a conically shaped aperture with a minor diameter of $3 \mathrm{~mm}$. A $30^{\circ}$ off-axis parabolic mirror with a focal length of $50.8 \mathrm{~mm}$ creates an intermediate image of the object inside the box close to the surface of the next, flat mirror. The half images of the two branches are then combined on the camera sensor to form a full wide angle view image. The detailed description of the wide angle imaging system is given in [39]. A rhodium film (175 nm thick) was evaporated directly on polished flat stainless steel mirrors $(60 \times 40 \mathrm{~mm})$. On the other hand, for the parabolic mirrors a $100 \mu \mathrm{m}$ amorphous electroless coating of a nickelphosphorus alloy was used on the polished stainless steel surface as an interlayer to reduce the micro roughness of the surface after polishing and to allow accurate surface shaping. The characterisations of the films were carried out on witness samples $(25 \mathrm{~mm}$ in diameter). The diffuse reflectivity was below $3 \%$ in the range $250-2500 \mathrm{~nm}$ and the specular reflectivity was similar to the reference one [3]. Reflectivity measurements were also performed at incidence angles of $40,50,60,70$ and $80^{\circ}$ for perpendicular (s) and parallel (p) polarized light with a spectral ellipsometer SENTECH S 850, and are identical to the reference one (Figure 5 in reference [3]). The reflectivity observed for a natural or unpolarized light, containing an equal mix of $s$ and p-polarisations is given by the sum of Rs and Rp divided by 2. Secondary Emmision Microscopy (SEM) observations show small crystallites (few tens of $\mathrm{nm}$ ) typical for evaporated Rh films [15]. For all tokamak as well as ITER, baking of vacuum chamber are performed. To simulate a really harsh baking a 6 hours annealing at $600{ }^{\circ} \mathrm{C}$ in air was carried out. Chemical analyses of the surface by x-ray Photon Spectroscopy (XPS) revealed a Rh metallic surface covered with adsorbed molecules (oxygen, carbon) and a thin rhodium oxide layer as described in our previous paper [3] but nothing else. No degradation of the optical reflectivity was observed after this annealing in contrary to Mo mirrors which oxidised in air [38] showing a reflectivity decrease of more than $10 \%$ in the visible range between the mirror production and JET installation. The system delivered the required image quality for JET plasma monitoring and wall protection.

For the 2013-2014 campaigns a new system, KL14, was installed in JET (Figure 1) using the lower left limiter guide tube. A mirror box identical to the previously described one is used and a new flat stainless steel mirror $(165 \times 80 \mathrm{~mm})$ coated also with $\mathrm{Rh}$ was added to guide the optical beam (Figure 2). This system was also given the same measurements quality. Monitoring discharges with identical plasma shape and operational parameters have been regularly executed to document the change in the optical 
performance of the wide angle systems [40]. Figure 3 shows the time evolution of typical monitoring pulses: pulse \#84570 directly after the installation of the new wide angle KL14 system and the pulse \#87402 at the end of the experimental campaign. These L-mode pulses with an additional NBIpower of about $1.2 \mathrm{MW}$ have been performed at $\mathrm{B}_{\mathrm{T}} \approx 2.0 \mathrm{~T}$, $I_{p}=2.0 \mathrm{MA}$ and safety factor $q 95=3.2$. For precise control of the changes of the optical performance it is important to keep the radial outer gap (ROG) as well as the inner gap (RIG) constant. The gap is the distance between the plasma surface (LCFS=Last Closed Flux Surface) and the first wall. Figure 4 shows the same values of RIG and ROG for the analysed pulses indicating the identical plasma shape. The central line-integrated plasma density as well as the $D_{\alpha}$ emission in the outer divertor were also identical.

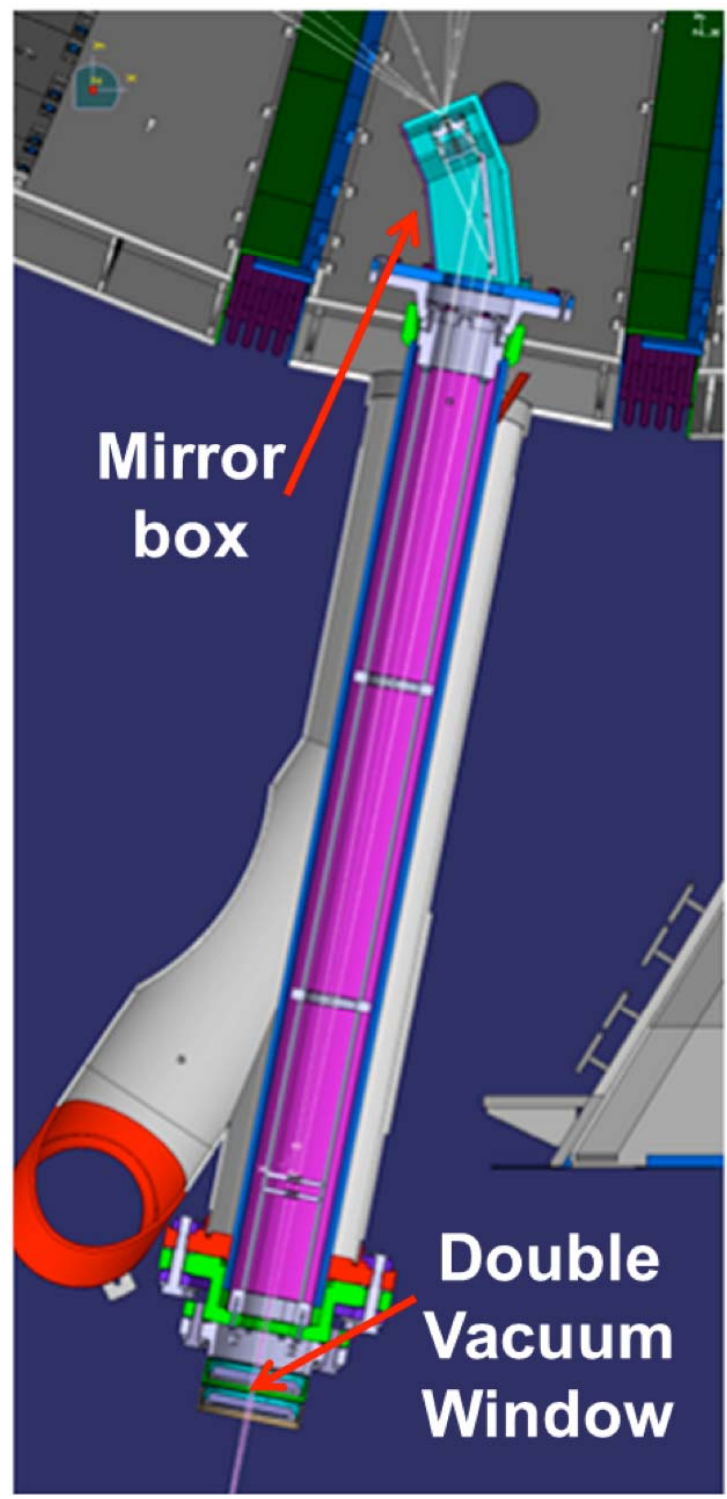

Figure 1: Schematic view from the top showing the optical path of the KL14 wide angle viewing system installed in the lower left limiter guide tube. The field of view of the system is tangential to the entire vessel including the wide outer poloidal limiter, re-ionisation plates, narrow outer poloidal limiter, lower hybrid antenna and inner wall guard limiters.

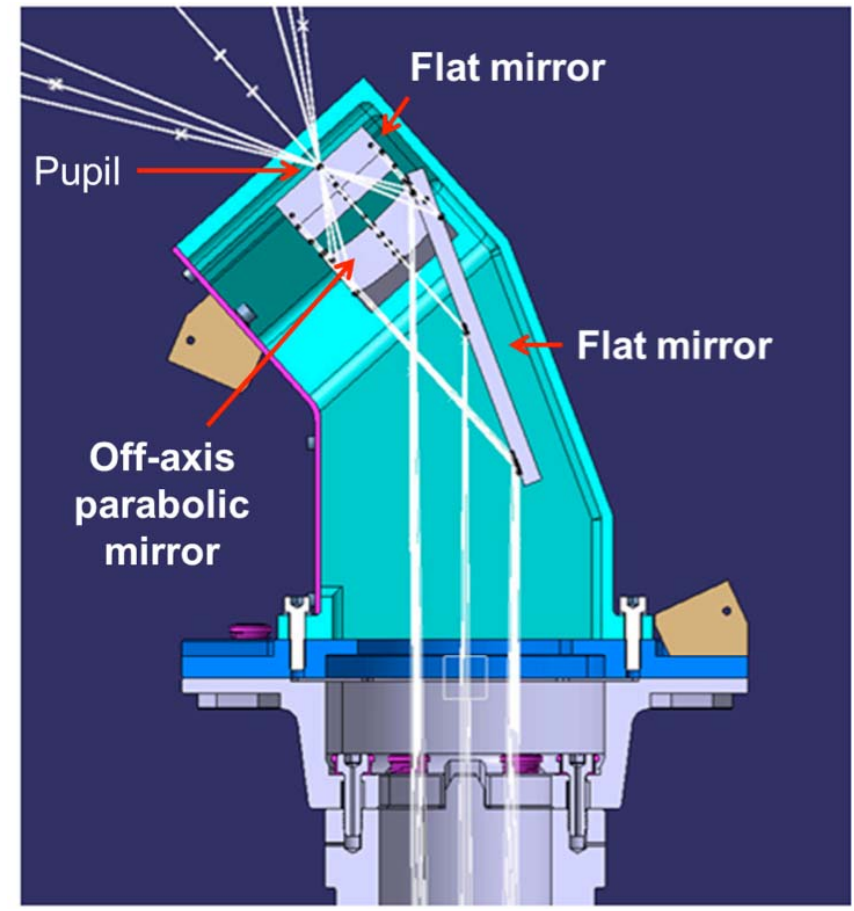

Figure 2: Top view of the mirror layout in the KL14 system including the optical path. The distance from the pupil to the plasma is around 20 centimetres, depending on the plasma configuration.

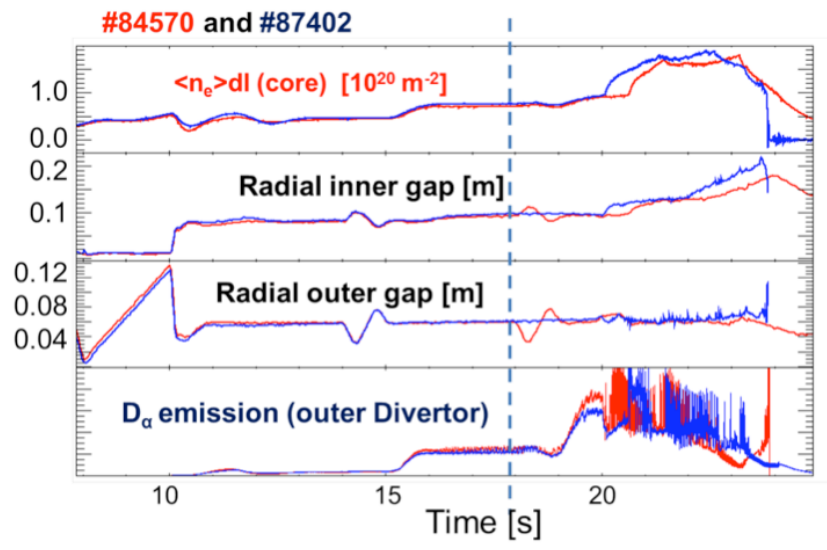

Figure 3: Time evolution of typical monitoring L-mode discharges which correspond to the next figure 5 .

The wide angle view imaging system contains two CCD cameras, colour and monochrome cameras, each of it equipped with telephoto zoom lenses set to a focal length of $250 \mathrm{~mm}$ and $300 \mathrm{~mm}$ consequently. An unfiltered colour CCD camera provides video images for general plasma operation monitoring in the visible spectral range. Figure $\mathbf{5}$ shows images taken by the colour camera directly after installation of the wide angle KL14 video systems (\#84570) and at the end of the experimental campaign (\#87402). No visible degradation of the images has been observed. The composite RGB signal of the unfiltered colour CCD camera has been split into three colour channels: Red: $580-750 \mathrm{~nm}$; Green: $475-570 \mathrm{~nm}$; Blue: $430-480 \mathrm{~nm}$. The colour channels have been compared for the mentioned two monitoring 


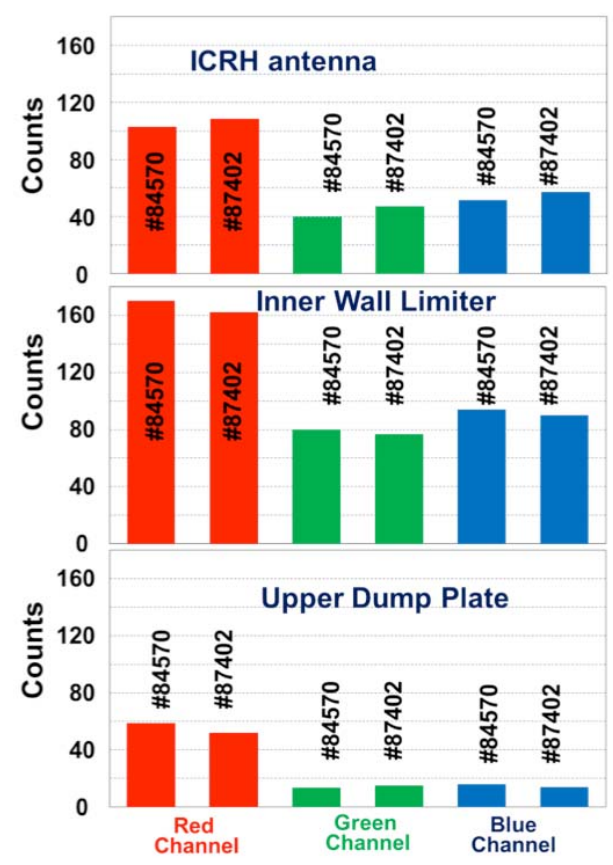

Figure 4: Comparison of the colours channels of the colour camera for two monitoring pulses: directly after the installation of the wide angle KL14 video systems (\#84570) and at the end of the experimental campaign (\#87402).

pulses in Figure 4. This figure shows the comparison for three region of the interest: ICRH antenna, Inner Wall Limiter, Upper dump plate. No or an insignificant degradation of the optical transmittance has been observed during one of the experimental C33 campaign (about 3000 plasma pulses in different magnetic field configurations).

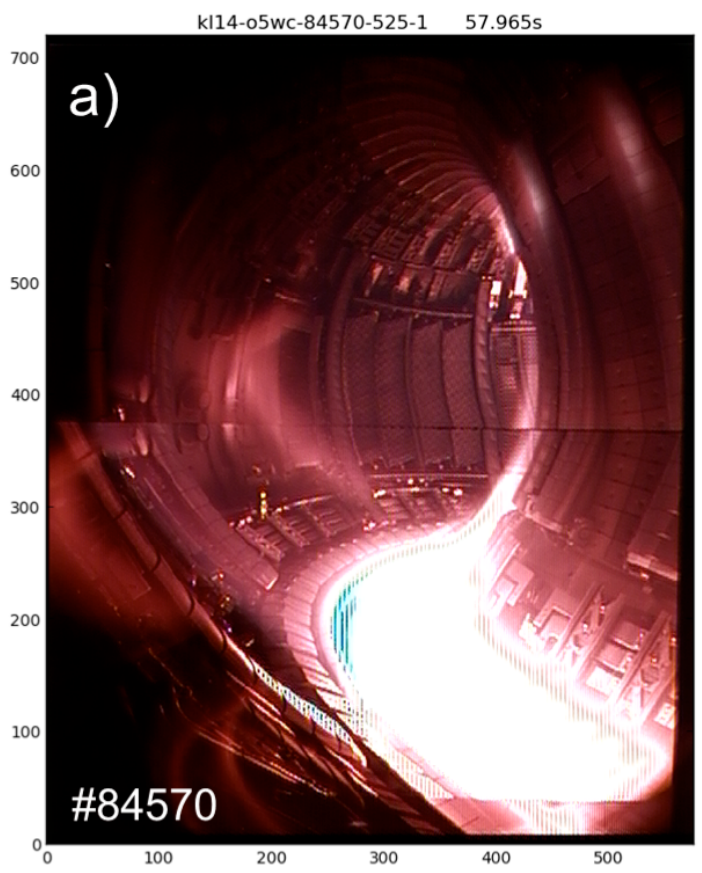

\section{CONCLUDING REMARKS}

Metallic coated mirrors were extensively studied for ITER's FM purpose concerning the manufacturing techniques, characterisations and laboratory tests. Thick coated Rh mock up delaminated at high flux exposure, which is a 1000-fold higher the $D(T)$ incident fluxes (up to $10^{20} \mathrm{~m}^{-2} \mathrm{~s}^{-1}$ ) that can be expected at the outer midplane wall of ITER [30], due to a high energy stored in the film. In case of the high flux plasma exposure in ITER, the coating parameters have to be adjusted to achieve a low compressive stress value i.e. a low energy stored in the film to avoid delamination. For an identical fluence but at a 100-fold lower flux level, tokamak tests in TEXTOR, DIII-D, JET-C and JET-ILW showed no critical failure of the coated mirrors like delamination or strong degradation of the optical properties. In case of Mo coatings exposed to $D_{2}$ plasma, delamination of coatings from the substrate as a result of high flux deuterium plasma exposure was also shown to be a possible risk, which can, however, be suppressed at elevated sample temperatures relevant to ITER. Moreover, irreversible mechanisms such as surface roughening or deuterium which is strongly bound to defect sites in the Rh lattice have a negligible contribution to the reflectivity degradation. Two complete diagnostics using $\mathrm{Rh}$ coated mirrors i.e. wide angle viewing systems were installed in JET-ILW, they delivered the required image quality for plasma monitoring and wall protection. Moreover, irreversible mechanisms such as surface roughening or deuterium which is strongly bound to defect sites in the $\mathrm{Rh}$ lattice have a negligible contribution to the reflectivity degradation. Furthermore, Mo and $\mathrm{Rh}$ coated mirrors irradiated under

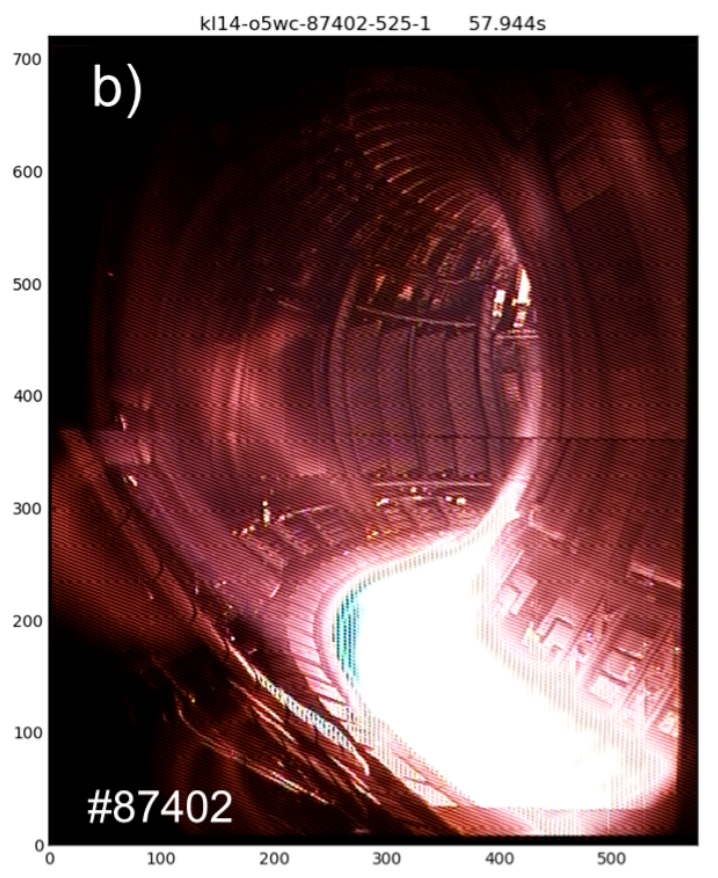

Figure 5: Two images taken by the colour cameras a) directly after the installation of the wide angle KL14 video systems (\#84570) and b) at the end of the experimental campaign (\#87402). Qualitatively no degradation of the picture can be observed, which is in line with results from quantitative comparisons at various key image areas (see Figure 4). 
neutrons (0.1 dpa) showed not more than few percent reflectivity losses in the visible and near infrared range.

For both systems a detailed ex-situ optical characterisation of the mirrors is foreseen in the future.

The mirror reflectivity would also suffer from the rough deposits from $W$ and beryllium grown on the surface; development of the in situ cleaning methods to be operated in the diagnostic modules started and first results on coated mirrors either by laser or plasma cleaning are encouraging [9].

\section{ACKNOWLEDGEMENTS}

This work has been carried out within the framework of the EURO fusion Consortium and has received funding from the Euratom research and training programme 2014-2018 under grant agreement No 633053. The views and opinions expressed herein do not necessarily reflect those of the European Commission. The authors would like to thank the Swiss Federal Office of Energy and the Federal Office for Education and Science for their financial support. This work was also supported by the Swiss National Foundation (SNF) and the Swiss Nanoscience Institute (SNI).

\section{REFERENCES}

[1] Walsh M, Andrew P, Barnsley R, et al. ITER diagnostic challenges, in: IEEE, 2011: pp. 1-8. http://dx.doi.org/10.1109/sofe.2011.6052210

[2] Brooks JN, Allain JP. Particle deposition and optical response of ITER motional Stark effect diagnostic first mirrors. Nucl Fusion 2008; 48: 045003.

http://dx.doi.org/10.1088/0029-5515/48/4/045003

[3] Marot L, De Temmerman G, Oelhafen P, Covarel G, Litnovsky A. Rhodium coated mirrors deposited by magnetron sputtering for fusion applications. Rev Sci Instrum 2007; 78: 103507.

\section{http://dx.doi.org/10.1063/1.2800779}

[4] Marot L, Mathys D, De Temmerman G, Oelhafen P. Characterization of sub-stoichiometric rhodium oxide deposited by magnetron sputtering. Surf Sci 2008;602: 3375-80. http://dx.doi.org/10.1016/i.susc.2008.09.012

[5] Marot L, Steiner R, De Temmerman G, Oelhafen P. Reactivity of rhodium during co-deposition of rhodium and carbon. J Nucl Mater 2009; 390-391: 1135-7.

http://dx.doi.org/10.1016/j.jnucmat.2009.01.266

[6] Bardamid A, Bryk V, Konovalov V, et al. Erosion of steel under bombardment with ions of a deuterium plasma. Vacuum 2000; 58: 1015.

\section{http://dx.doi.org/10.1016/S0042-207X(00)00227-X}

[7] Wisse M, Eren B, Marot L, Steiner R, Meyer E. Spectroscopic reflectometry of mirror surfaces during plasma exposure. Rev Sci Instrum 2012; 83: 013509. http://dx.doi.org/10.1063/1.3678640

[8] Voitsenya VS, Balden M, Bardamid AF, et al. Development of surface relief on polycrystalline metals due to sputtering. Nucl Instrum Methods Phys Res Sect B Beam Interact Mater At 2013; 302: 32-9. http://dx.doi.org/10.1016/..nimb.2013.03.005

[9] Voitsenya VS, Bardamid AF, Donné AJH. Experimental simulation of the behaviour of diagnostic first mirrors fabricated of different metals for ITER conditions, Accepted in The Open Optics Journal. (2015).

[10] Bennett HE, Porteus JO. Relation between surface roughness and specular reflectance at normal incidence. J Opt Soc Am 1961; 51: 123.

http://dx.doi.org/10.1364/JOSA.51.000123

[11] Voitsenya VS, Bardamid AF, Belyaeva Al, et al. Modification of optical characteristics of metallic amorphous mirrors under ion bombardment. Plasma Devices Oper 2009; 17: 144-54. http://dx.doi.org/10.1080/10519990902903595
[12] Bardamid AF, Voitsenya VS, Davis JW, et al. Comparison of the behavior of $\operatorname{Zr}(41.2 \%) \mathrm{Ti}(13.8 \%) \mathrm{Cu}(12.5 \%) \mathrm{Ni}(10 \%) \mathrm{Be}(22.5 \%)$ amorphous and crystallized mirrors under deuterium ion bombardment. J Alloys Compd 2012; 514: 189-94.

http://dx.doi.org/10.1016/i.jallcom.2011.11.062

[13] Orlovskiy I, Alekseev A, Andreenko E, et al. Thermal testing of the first mirror unit mock-up for $\mathrm{H}$-alpha and visible spectroscopy in ITER. Fusion Eng Des 2015; 96-97: 899-902.

http://dx.doi.org/10.1016/i.fusengdes.2015.02.049

[14] Marot L, De Temmerman G, Thommen V, Mathys D, Oelhafen P. Characterization of magnetron sputtered rhodium films for reflective coatings. Surf Coat Technol 2008; 202: 2837-43. http://dx.doi.org/10.1016/i.surfcoat.2007.10.014

[15] Eren B, Marot L, Litnovsky A, et al. Reflective metallic coatings for first mirrors on ITER. Fusion Eng Des 2011; 86: 2593-6. http://dx.doi.org/10.1016/j.fusengdes.2010.12.038

[16] Passoni M, Dellasega D, Grosso G, Conti C, Ubaldi MC, Bottani CE. Nanostructured rhodium films produced by pulsed laser deposition for nuclear fusion applications. J Nucl Mater 2010; 404: 1-5. http://dx.doi.org/10.1016/i.jnucmat.2010.06.015

[17] Uccello A, Dellasega D, Perissinotto S, Lecis N, Passoni M. Nanostructured rhodium films for advanced mirrors produced by Pulsed Laser Deposition. J Nucl Mater 2013; 432: 261-5. http://dx.doi.org/10.1016/j.jnucmat.2012.08.046

[18] Mostako ATT, Rao CVS, Khare A. Mirror-like pulsed laser deposited tungsten thin film. Rev Sci Instrum 2011; 82: 013101. http://dx.doi.org/10.1063/1.3529441

[19] Razdobarin AG, Mukhin EE, Semenov VV, et al. Diagnostic mirrors with transparent protection layer for ITER. Fusion Eng Des 2011; 86: $1341-4$.

http://dx.doi.org/10.1016/i.fusengdes.2011.02.052

[20] Mukhin EE, Semenov VV, Razdobarin AG, et al. First mirrors in ITER: material choice and deposition prevention/cleaning techniques. Nucl Fusion 2012; 52: 013017. http://dx.doi.org/10.1088/0029-5515/52/1/013017

[21] Joanny M, Travere JM, Salasca S, et al. Achievements on engineering and manufacturing of ITER first-mirror mock-ups. IEEE Trans Plasma Sci 2012; 40: 692-6. http://dx.doi.org/10.1109/TPS.2011.2181539

[22] Marot L, Covarel G, Tuilier M-H, Steiner R, Oelhafen P. Adhesion of rhodium films on metallic substrates. Thin Solid Films 2008; 516: 7604-8.

http://dx.doi.org/10.1016/i.tsf.2008.04.087

[23] Eren B, Marot L, Wisse M, et al. In situ evaluation of the reflectivity of molybdenum and rhodium coatings in an ITER-like mixed environment. J Nucl Mater 2013; 438: S852-5. http://dx.doi.org/10.1016/i.jnucmat.2013.01.184

[24] Marot L, Steiner R, Gantenbein M, Mathys D, Meyer E. Co-deposition of rhodium and tungsten films for the first-mirror on ITER. J Nucl Mater 2011; 415: S1203-5.

http://dx.doi.org/10.1016/i.jnucmat.2010.08.062

[25] Eren B, Wisse M, Marot L, Steiner R, Meyer E. Deuterium plasma exposure on rhodium: Reflectivity monitoring and evidence of subsurface deuteride formation. Appl Surf Sci 2013; 273: 94-100. http://dx.doi.org/10.1016/j.apsusc.2013.01.194

[26] Bardamid AF, Belyaeva Al, Davis JW, et al. Optical properties of Al mirrors under impact of deuterium plasma ions in experiments simulating ITER conditions, J. Nucl. Mater. 393 (2009) 473-480. http://dx.doi.org/10.1016/i.jnucmat.2009.07.003

[27] A. Uccello, B. Eren, L. Marot, D. Dellasega, A. Maffini, R. Steiner, et al., Deuterium plasma exposure of rhodium films: Role of morphology and crystal structure. J Nucl Mater 2014; 446: 106-12. http://dx.doi.org/10.1016/i.jnucmat.2013.11.023

[28] Eren B, Marot L, Langer M, et al. The effect of low temperature deuterium plasma on molybdenum reflectivity. Nucl Fusion 2011; 51: 103025.

http://dx.doi.org/10.1088/0029-5515/51/10/103025

[29] Eren B, Marot L, Ryzhkov IV, et al. Roughening and reflection performance of molybdenum coatings exposed to a high-flux deuterium plasma. Nucl Fusion 2013; 53: 113013. http://dx.doi.org/10.1088/0029-5515/53/11/113013

[30] Kotov V, Reiter D, Kukushkin AS, Pacher HD. Numerical estimates of the ITER first mirrors degradation due to atomic fluxes. Fusion Eng Des 2011; 86: 1583-6.

http://dx.doi.org/10.1016/ifusengdes.2010.12.048

[31] Marot L, De Temmerman G, van den Berg MA, et al. ITER first mirror mock-ups exposed in Magnum-PSI. Submitted to Nucl Fusion (2015). 
[32] Litnovsky A, Rubel M, Garcia-Carrasco A, et al. 25th Meeting of the ITPA Diagnostics Topical Group, NIFS, Toki, Gifu, Japan 19-22 May 2015, Report of the Specialists Working Group on First Mirrors, (2015).

https://portal.iter.org/departments/POP/ITPA/Diag/DIAG/Document \%20Library/31/2.\%20ITPA\%20DAY\%201/13.Litnovski.FMWG.report .pdf

[33] Matveeva M, Litnovsky A, Marot L, et al. Material choice for first ITER mirrors under erosion conditions, in: 37th EPS Conf Plasma Phys. Dublin Irel., 2010.

http://ocs.ciemat.es/EPS2010PAP/pdf/P2.105.pdf

[34] Matveeva M. Influence of the surface composition and morphology on the reflectivity of diagnostic mirrors in a fusion reactor, Thesis, University Duesseldorf, 2014

http://docserv.uni-duesseldorf.de/servlets/DerivateServlet/Derivate36460/Matveeva PhD\%20Thesis HHU.pdf.

[35] Marot L, Oelhafen P, Temmerman GD, Rudakov DL, Litnovsky A, Simakov S. Coated mirrors for ITER, in: 13th ITPA Diagn. Meet. Chengdu China, 2007.

https://portal.iter.org/departments/POP/

ITPA/Diag/DIAG/Document\%20Library/21/Marot.mirrors.pdf
[36] Marot L, Meyer E, Rubel M, et al. Performances of Rh and Mo mirrors under JET exposure. J Nucl Mater 2013; 438: S1187-91. http://www.sciencedirect.com/science/article/pii/S0022311513002 705

[37] Rubel M, Ivanova D, Coad JP, et al. Overview of the second stage in the comprehensive mirrors test in JET. Phys Scr 2011; T145: 014070. http://iopscience.iop.org/article/10.1088/0031-8949/2011/T145/ $014070 /$ meta

[38] Ivanova D, Rubel M, Widdowson A, et al. An overview of the comprehensive First Mirror Test in JET with ITER-like wall. Phys Sc 2014; T159: 014011.

http://dx.doi.org/10.1088/0031-8949/2014/T159/014011

[39] Clever M, Arnoux G, Balshaw N, et al. A wide angle view imaging diagnostic with all reflective, in-vessel optics at JET. Fusion Eng Des 2013; 88: 1342-6.

http://dx.doi.org/10.1016/.jusengdes.2013.01.038

[40] Coenen JW, Sertoli M, Brezinsek S, et al. Long-term evolution of the impurity composition and impurity events with the ITER-like wall at JET. Nucl Fusion 2013; 53: 073043.

http://dx.doi.org/10.1088/0029-5515/53/7/073043

(C) 2015 Marot et al.; Licensee Lifescience Global.

This is an open access article licensed under the terms of the Creative Commons Attribution Non-Commercial License (http://creativecommons.org/licenses/by-nc/3.0/) which permits unrestricted, non-commercial use, distribution and reproduction in any medium, provided the work is properly cited. 